\title{
Age is associated with time in therapeutic range for warfarin therapy in patients with atrial fibrillation
}

\author{
Leiliane Rodrigues Marcatto1,*, Luciana Sacilotto ${ }^{2, *}$, Francisco Carlos da Costa \\ Darrieux ${ }^{2}$, Denise Tessariol Hachul ${ }^{2}$, Maurício Ibrahim Scanavacca ${ }^{2}$, Jose Eduardo \\ Krieger ${ }^{1}$, Alexandre Costa Pereira ${ }^{1}$ and Paulo Caleb Junior Lima Santos ${ }^{1}$ \\ ${ }^{1}$ Laboratory of Genetics and Molecular Cardiology, Heart Institute (InCor), University of São Paulo Medical School, São \\ Paulo, Brazil \\ ${ }^{2}$ Clinical Cardiology Division, Heart Institute (InCor), University of São Paulo Medical School, São Paulo, Brazil \\ * These authors have contributed equally to this work \\ Correspondence to: Alexandre Costa Pereira, email: alexandre.pereira@incor.usp.br
}

Paulo Caleb Junior Lima Santos, email: pacaleb@usp.br

Keywords: warfarin, TTR, age, atrial fibrillation, polymorphisms, Gerotarget

Received: May 03, $2016 \quad$ Accepted: July 19, $2016 \quad$ Published: July 29, 2016

\section{ABSTRACT}

Background: Warfarin is the most prescribed oral anticoagulant used for preventing stroke in patients with atrial fibrillation. Time in the therapeutic range (TTR) has been accepted as the best method to evaluate the quality of warfarin therapy. The main aim of the present study was to evaluate the impact of variables on the time in the therapeutic range for warfarin therapy in patients with atrial fibrillation from a referral cardiovascular hospital.

Methods: This retrospective study included 443 patients were included (190 patients with age $<65$ years and 253 patients with age $\geq 65$ years) from 2011 to 2014 and TTR was computed according to Rosendaal's method.

Results: Patients with age $\geq 65$ years had higher TTR value $(67 \pm 22 \%)$ compared with patients with $<65$ years $(60 \pm 24 \%)(p=0.004)$. In a linear regression model, only age $\geq 65$ years emerged as a significant predictor of greater TTR values. In multivariate logistic regression model, the variable age $\geq \mathbf{6 5}$ years was associated with higher OR for having a TTR higher than the median value $(O R=2.17, p<0.001)$.

Conclusion: We suggest that the age influenced TTR through greater drug adherence. Strategies for increasing drug adherence might improve quality of warfarin anticoagulation.

\section{BACKGROUND}

Atrial fibrillation (AF) is the most common cardiac arrhythmia and it has a high estimated prevalence of 33.5 million people in worldwide [1,2]. The prevalence of this disease increases with age from $<0.5 \%$ between 40 and 50 years, to $5 \%$ to $15 \%$ at $>80$ years of age [3]. AF may be associated with severe consequences, like stroke with neurological deficit and death [4]. Anticoagulation therapy is the most important measure for preventing stroke in the AF setting.

Warfarin is the most commonly used oral anticoagulant for preventing stroke in patients with $\mathrm{AF}$. However, this drug has a narrow therapeutic index and a large inter-individual variability in dose requirements $[5$, 6]. Thus, clinicians use the international normalized ratio (INR) for monitoring the warfarin therapy. High values of INR are associated with bleeding while low values of INR are associated with thromboembolism and stroke [7, 8]. INR values are used to calculate the time in the therapeutic range (TTR).

TTR is a measure of quality of anticoagulation therapy and high TTR values mean a good quality of treatment $[9,10]$. A study conducted in Europe, included 6,250 patients with AF using warfarin from different countries, showed that TTR levels ranged from $66.0 \%$ in Italy to $72.6 \%$ in the United Kingdom. In France, Germany, and Italy, less than $50 \%$ of the patients had TTR 
Table 1: Demographic and clinical characteristics of participating patients according to age over 65 years

\begin{tabular}{|l|l|l|l|}
\hline Variable & $\begin{array}{l}<\mathbf{6 5} \text { years } \\
\boldsymbol{n} \mathbf{1 9 0}\end{array}$ & $\begin{array}{l}\mathbf{2 6 5} \text { years } \\
\boldsymbol{n} \mathbf{2 5 3}\end{array}$ & $\boldsymbol{p}$ value \\
\hline Sex, female (\%) & 45.8 & 41.5 & 0.37 \\
\hline Self-declared race, White (\%) & 59.3 & 73.9 & $\mathbf{0 . 0 0 1}$ \\
\hline Body mass index (Kg/m $)^{2}$ & $27.7 \pm 5.2$ & $26.9 \pm 4.4$ & 0.11 \\
\hline Smoking (\%) & 7.0 & 4.8 & 0.33 \\
\hline Diabetes mellitus (\%) & 19.1 & 28.5 & $\mathbf{0 . 0 3}$ \\
\hline Hypertension (\%) & 88.9 & 87.4 & 0.62 \\
\hline Hyperlipidemia (\%) & 41.7 & 45.5 & 0.43 \\
\hline Heart failure (\%) & 33.9 & 29.8 & 0.36 \\
\hline Warfarin dose (mg/week) & $28.8 \pm 12.5$ & $26.8 \pm 11.5$ & 0.08 \\
\hline Amiodarone use (\%) & 18.9 & 15.9 & 0.40 \\
\hline Time in warfarin therapy (years) & $5.0 \pm 4.6$ & $6.2 \pm 5.0$ & $\mathbf{0 . 0 2}$ \\
\hline CYP2C9 genotypes (IM+PM) (\%) & 27.1 & 27.3 & 0.97 \\
\hline VKORC1 genotypes, GG/GA/AA (\%) & $47.9 / 42.6 / 9.5$ & $43.4 / 47.8 / 8.8$ & 0.55 \\
\hline
\end{tabular}

Table 2: Mean TTR according to age over 65 years

\begin{tabular}{|c|c|c|c|}
\hline & \multicolumn{2}{|c|}{ TTR (\%) } & \\
\hline & $<65$ years & $\geq 65$ years & $p$ value \\
\hline Total group $(n=443)$ & $60 \pm 24$ & $67 \pm 22$ & 0.004 \\
\hline Female $(n=192)$ & $61 \pm 23$ & $66 \pm 21$ & 0.04 \\
\hline Male $(n=251)$ & $59 \pm 25$ & $68 \pm 23$ & 0.01 \\
\hline
\end{tabular}

$>70 \%$ [11]. Another study, including 377 patients and considering TTR $<60 \%$ as a marker of poor quality in the anticoagulation control, showed that $44.3 \%$ of the patients had a poor anticoagulation therapy [12].

Age, body mass index, concomitant drugs, patient adherence and genetic factors can influence INR values [13-15]. However, the factors which can significantly influence TTR measures, i.e., warfarin anticoagulation therapy in the long-term are not fully understood [9, 16]. Identification of factors that influence TTR values is important to guide the best clinical approach during the treatment. In this scenario, the main aim of the present study was to evaluate the impact of variables on the TTR for warfarin therapy in patients with AF from a referral cardiovascular hospital.

\section{RESULTS}

Table 1 shows demographic and clinical characteristics of the patients according to age over 65 years. Mean age in the younger group was $56 \pm 9$ years $(n$ $=190)$ and in the older was $73 \pm 6$ years $(n=253)$. We observed higher percentages of self-declared White, diabetes mellitus, and time in warfarin therapy in the group of patients with age $\geq 65$ years compared with group of patients with age $<65$ years.

Table 2 shows TTR mean according to age over 65 years. We observed that, in the overall group, patients with age $\geq 65$ years had higher TTR mean than patients with age $<65$ years $(67 \pm 22 \%$ and $60 \pm 24 \%, p=0.004$, respectively).
We also observed higher TTR mean in patients with age $\geq 65$ years than patient with age $<65$ years in the female group $(66 \pm 21 \%$ and $61 \pm 23 \%, p=0.04$, respectively) and in the male group $(68 \pm 23 \%$ and $59 \pm 25 \%, p=0.01$, respectively). The variable self-declared race was not associated with TTR, even in multivariate models. The TTR mean of the White and non-White groups were not different ( $64 \pm 23 \%$ and $62 \pm 23 \%, p=0.24$, respectively).

In a multivariate linear regression model, we analyzed the effect of variables, including age, in years, on TTR values (Table 3 ). We show that age was also associated with TTR values $(p=0.02)$. Supplementary table 1 shows a linear regression model with the addition of other variables.

In a multivariate logistic regression model, we analyzed TTR median $(\geq 68.0 \%)$ as a dependent variable and the following variables as independent: age $\geq 65$ years, sex (male), self-declared race (White), BMI, smoking, amiodarone use, $C Y P 2 C 9$ predicted metabolic phenotypes (IM+PM) and $V K O R C 1$ genotypes (Table 4). The variable age $\geq 65$ years was significantly associated with having a TTR value above the median $(\mathrm{OR}=2.17,95 \% \mathrm{CI}=1.43$ $3.28, p<0.001)$. Supplementary Table 2 shows a logistic regression model including other independent variables.

\section{DISCUSSION}

In the present study, our main finding was that patients with age $\geq 65$ years had higher TTR value than those with age $<65$ years. Interestingly, few studies have 
Table 3: Multivariate linear regression analysis for TTR

\begin{tabular}{|l|l|l|}
\hline Variable & $\boldsymbol{\beta}$ standardized coefficient & $\boldsymbol{p}$ value \\
\hline Age & 0.121 & $\mathbf{0 . 0 2}$ \\
\hline Sex (male) & 0.007 & 0.88 \\
\hline Self-declared race (White) & 0.050 & 0.33 \\
\hline Body mass index & 0.029 & 0.57 \\
\hline Smoking & -0.018 & 0.72 \\
\hline Amiodarone use & -0.008 & 0.88 \\
\hline CYP2C9 genotypes (IM+PM) & 0.006 & 0.91 \\
\hline VKORC1 genotypes & 0.006 & 0.90 \\
\hline
\end{tabular}

Table 4: Multivariate logistic regression analysis for over values of TTR median $(\geq 68.0 \%)$

\begin{tabular}{|l|l|l|l|}
\hline Variables & OR & $\mathbf{9 5 \%}$ CI & $\boldsymbol{p}$ value \\
\hline$\geq \mathbf{6 5}$ years & 2.17 & $1.43-3.28$ & $<\mathbf{0 . 0 0 1}$ \\
\hline Sex (male) & 1.34 & $0.89-2.01$ & 0.16 \\
\hline Self-declared race (White) & 1.36 & $0.87-2.12$ & 0.18 \\
\hline Body mass index & 1.01 & $0.97-1.06$ & 0.56 \\
\hline Amiodarone use & 0.99 & $0.59-1.67$ & 0.97 \\
\hline CYP2C9 genotypes (IM+PM) & 1.22 & $0.78-1.91$ & 0.39 \\
\hline VKORC1 genotypes & 0.99 & $0.72-1.37$ & 0.96 \\
\hline
\end{tabular}

showed this same association. A study including 501 Japanese patients to evaluate factors influencing TTR, such as age, gender, antiplatelet drugs, $\mathrm{CHADS}_{2}$ score and warfarin dose showed that patients aged $\geq 70$ years had TTR of $77 \pm 17 \%$ and patients aged $<70$ years had TTR of $46 \pm 23 \%$ ( $p<0.001$ ) [16]. Another study, including 6,983 patients from diverse regions of the world, showed that patients with age $<73$ years had lower TTR mean levels than patients with age $\geq 73$ years ( $53.6 \pm 20.9$ vs $56.8 \pm 21.5$, respectively, $p<0.001$ ) [9]. Furthermore, Skeppholm et al showed that younger patients spent more time out of therapeutic range than older patients [17].

We suggest that TTR can be influenced by age presumably because older people have higher compliance (drug adherence) than younger. Here, we chose the age according to the definition of elderly person by WHO (World Health Organization) [18]. Indeed, it has been showed that age younger than 65 years was a risk factor for non-adherence to warfarin [19-21]. Witt et al showed that mean age was higher in patients adherent than in patients non-adherent (70.9 years $v s 63.8$ years; $p<0.001$ ) [20]. A study examined the medication taking behavior of older adults. They found that age, gender, education level, marital status, living status and health belief affected the medication knowledge and behavior. They also showed that younger patients had a limited knowledge about their disease and this may be a reason for non-adherence [22]. The greatest adherence to treatment by older people might also be influenced for greater severity of illness and successful compliance behavior by caregivers at home [23]. Another study showed that elderly patients were more adherent to medications after hospital discharge, had an increased interaction with the healthcare system (appointments, number of physician interactions), had higher knowledge about the importance of chronic medication management and had a higher level of experience with managing medications [24]. In the present study, we observed difference in time in warfarin therapy, in years (5.0 $\pm 4.6 v s 6.2 \pm 5.0)$, according to age group. However, we showed that this small difference did not affect TTR values in a multivariate analysis.

A recent study showed that TTR is an independent predictor of major adverse cardiovascular events in their cohort of AF patients. Moreover, the authors showed that age were positively associated to major adverse cardiovascular events and a good anticoagulation is associated with a reduction of these events [25].

Sex and self-declared race did not influence the TTR in our analysis. Okumura et al also did not find differences in TTR mean according sex [16]. However, Singer et al showed that male patients had higher TTR than female patients $(56.4 \pm 21.2$ vs $53.3 \pm 21.3 p<0.001)$; and Rose et al showed that the group with TTR $>75 \%$ had the lowest proportion of females (37.9\%) compared to the group with TTR $<60 \%(46.5 \%, p<0.001)[9,26]$. Bhandari et al reported that African-American patients spent less time in range compared with White-American patients (32.2\% vs $42.0 \%, p<0.001)$ [27]. Another study showed that African-Americans spent more time in the sub-therapeutic range (INR < 2) [28].

Neither warfarin dose nor CYP2C9 and $V K O R C 1$ polymorphisms influence TTR in the present study. However, Okumura et al. found that warfarin dose affected TTR, patients with a low dose $(<2.5 \mathrm{mg} /$ day $)$ had higher TTR compared to patients with higher dose $(\geq 5.0 \mathrm{mg} /$ day) $(72 \pm 22 \% ; 48 \pm 24 \% ; p<0.001)$. They suggested 
that age might have affected the dose administered by the physician. Patients aged $<70$ years had higher dose (3.5 $\pm 1.2 \mathrm{mg} /$ day) than patients aged $\geq 70$ years $(2.7 \pm 1.0 \mathrm{mg} /$ day). However, after multivariate analysis, they showed that warfarin dose remained an independent predictor of TTR [16]. Importantly, in our study, the variable age did not affect warfarin dose. Some studies showed that CYP2C9 and VKORC1 polymorphisms influenced TTR mean during initiation of therapy with warfarin $[14,15$, 29]. We did not find this association probably because our patient group were anticoagulated for at least 12 months.

The variables diabetes mellitus, hypertension and heart failure did not influence TTR mean in our study. These variables are components of the $\mathrm{CHADS}_{2}$ score, which estimates stroke risk in patients with atrial fibrillation. Other variables compose the score, such as age $\geq 75$ and a history of stroke or transient ischemic attack symptoms [30, 31]. Okuwura et al. found that $\mathrm{CHADS}_{2}$ score influenced TTR. Patients with a score $\leq 1$ had TTR of $59 \pm 27 \%$ and patients with a score $\geq 2$ had $68 \pm 23 \%$. The authors explained this finding by the fact that the age of the patients with a score $\geq 2$ ( $73 \pm 8$ years) was significantly higher than those patients with a score $\leq 1$ ( $65 \pm 11$ years $)$ $(p<0.001)$ [16]. On the contrary, Singer et al found that patients with higher $\mathrm{CHADS}_{2}$ score $(\geq 2)$ had lower TTR mean levels (score $\leq 2$ : TTR $=59.3 \pm 19.7$; score $3-6$ : TTR $<55.1 \pm 21.3 ; p<0.01)$ [9]. Furthermore, another study showed that $\mathrm{CHADS}_{2}$ score did not influence TTR [26]. In addition, Singer et al. showed that patients with heart failure had lower TTR mean levels (52.9 $\pm 21.2 \mathrm{vs}$ $59.0 \pm 20.7 p<0.001$ ) [9] and Rose et al. found that heart failure was associated with poor control (TTR $<60 \%=$ $26.1 \%$ vs TTR $>75 \%=20.5 \% p<0.001)$ [26].

Our study has some potential limitations. First, we were not able to use SAMe TT2R2 score in patients with kidney and liver diseases, because we excluded these patients. Second, we did not apply questionnaires about drug adherence; thus, we were not able to test our hypothesis that the elderly had more drug adherence. Furthermore, we did not assess diet, which might be different according to the age group. Second, the influence of the variables on TTR depends on the characteristics of the patient sample. Our sample included patients with atrial fibrillation treated for at least 12 months with warfarin in a referral hospital. Our findings can be different from those of others because of the specifics of our casuistic.

White et al, analyzing the outcome of 3,587 patients with warfarin therapy from SPORTIF III and IV, indicated that the risks of death, myocardial function and stroke or systemic embolic event were lower in patients with TTR $\geq 60 \%$ than in those with TTR $<60 \%$ [10]. Here, we highlight the importance of studying variables that may influence TTR levels. We showed that age is associated with TTR. We suggest that age influenced TTR through greater drug adherence. Strategies for increasing drug adherence might improve the quality of warfarin anticoagulation.

\section{MATERIALS AND METHODS}

\section{Patients and study design}

This retrospective study included 443 patients with non-valvular AF treated with warfarin for at least 12 months, from 2011 to 2014, from a referral cardiovascular hospital [32]. The Institutional Ethics Committee (Register Number 0804/10) approved the study protocol and written informed consent was obtained from all participants prior to entering the study. The exclusion criteria were patients with chronic liver failure, using other anticoagulant drugs, receiving chemotherapy, and alcoholism. We obtained data regarding current drug use through a standardized interview with a pharmacist and checked electronic medical records.

\section{Measures and outcomes}

We used prothrombin time (PT) for evaluating oral anticoagulant therapy and obtained the INR calculation by the ratio PT of the patient/normal PT controls, elevated to the international sensitivity index $[6,33]$. We collected blood samples to assess current INR and DNA analysis. Besides, we checked past INR values in electronic medical records from the 12 months preceding enrollment. We calculated TTR of the past 12 months using the Rosendaal method [34], which uses linear interpolation to assign an INR value to each day between successive observed INR values.

Genotyping of $C Y P 2 C 9 * 2$ (c.430C > T, rs1799853), CYP2C9*3 (c.1075A > C, rs1057910), and VKORC1 3673 (g.1639G > A, rs9923231) polymorphisms was carried out by polymerase chain reaction followed by restriction enzyme digestion $[35,36]$. As quality control, $6 \%$ of the samples were reanalyzed and gave identical results. Patients were divided into distinct predicted phenotypes: extensive metabolizer (EM: wild-type genotypes for the CYP2C9 polymorphisms - *1/*1), intermediate metabolizer (IM: heterozygous genotypes for the loss-offunction CYP2C9 polymorphisms - *1/*2 or * $1 / * 3$ ) and poor metabolizer (PM: mutant homozygous or compound heterozygous genotypes for the loss-of-function CYP2C9 polymorphisms - $* 2 / * 2$ or $* 3 / * 3$ or $* 2 / * 3$ ) [37].

\section{Statistical analysis}

We present categorical variables as percentages and continuous variables as mean \pm standard deviation. We divided patients into groups according to age: patients 
with $<65$ years and patients with $\geq 65$ years [38]. TTR was adjusted for age, sex, BMI (body mass index), and selfdeclared race. We tested the effect of the age (in years) on TTR values in a multivariate linear regression model including the following independent variables: age, sex, BMI, race, smoking, amiodarone use, CYP2C9 genotypes (EM, IM or PM), and VKORC1 genotypes. In addition, we performed a multivariate logistic regression model to evaluate factors associated with values of TTR above median ( $\geq 68.0 \%$ ), including the following variables: age ( $\geq 65$ years), sex (male), BMI, self-declared race (White), smoking, amiodarone use, CYP2C9 genotypes (IM+PM), and $V K O R C 1$ genotypes. All statistical analyses were carried out using SPSS software (v. 16.0) and the level of significance set at $p \leq 0.05$.

\section{ACKNOWLEDGMENTS}

PCJL Santos is recipient from fellowship from FAPESP. The technical assistance of the Laboratory of Genetics and Molecular Cardiology group and Heart Institute (InCor) is gratefully acknowledged.

\section{CONFLICTS OF INTERESTS} interests.

The authors declare that they have no competing

\section{GRANT SUPPORT}

FAPESP, Brazil, Proc.2013/09295-3.

\section{REFERENCES}

1. Feinberg W.M., Blackshear JL, Laupacis A, Kronmal R, Hart RG. Prevalence, age distribution, and gender of patients with atrial fibrillation. Analysis and implications. Arch Intern Med. 1995; 155: 469-73.

2. Chugh SS, Havmoeller R, Narayanan K, Singh D, Rienstra M, Benjamin EJ, Gillum RF, Kim YH, McAnulty JHJr, Zheng ZJ, Forouzanfar MH, Naghavi M, Mensah GA, et al. Worldwide epidemiology of atrial fibrillation: a Global Burden of Disease 2010 Study. Circulation. 2014; 129: 83747.

3. Camm, AJ, Kirchhof P, Lip GY, Schotten U, Savelieva I, Ernst S, Van Gelder I C, Al-Attar N, Hindricks G, Prendergast B, Heidbuchel H, Alfieri O, Angelini A, et al. Guidelines for the management of atrial fibrillation: the Task Force for the Management of Atrial Fibrillation of the European Society of Cardiology (ESC). Eur Heart J. 2010; 31: 2369-429.

4. Psaty BM, Manolio TA, Kuller LH, Kronmal RA, Cushman M, Fried LP, White R, Furberg CD, Rautaharju PM. Incidence of and risk factors for atrial fibrillation in older adults. Circulation. 1997; 96: 2455-61.
5. Ageno W, Gallus AS, Wittkowsky A, Crowther M, Hylek EM, Palareti G. Oral anticoagulant therapy: Antithrombotic Therapy and Prevention of Thrombosis, 9th ed: American College of Chest Physicians Evidence-Based Clinical Practice Guidelines. Chest. 2012; 141: e44S-88S.

6. Guyatt GH, Eikelboom JW, Gould MK, Garcia DA, Crowther M, Murad MH, Kahn SR, Falck-Ytter Y, Francis CW, Lansberg MG, Akl EA, Hirsh J. Approach to outcome measurement in the prevention of thrombosis in surgical and medical patients: Antithrombotic Therapy and Prevention of Thrombosis, 9th ed: American College of Chest Physicians Evidence-Based Clinical Practice Guidelines. Chest. 2012; 141: e185S-94S.

7. Bleeding during antithrombotic therapy in patients with atrial fibrillation. The Stroke Prevention in Atrial Fibrillation Investigators. Arch Intern Med. 1996; 156: 40916.

8. Adjusted-dose warfarin versus low-intensity, fixed-dose warfarin plus aspirin for high-risk patients with atrial fibrillation: Stroke Prevention in Atrial Fibrillation III randomised clinical trial. Lancet. 1996; 348: 633-8.

9. Singer DE, Hellkamp AS, Piccini JP, Mahaffey KW, Lokhnygina Y, Pan G, Halperin JL, Becker RC, Breithardt G, Hankey GJ, Hacke W, Nessel CC, Patel MR, et al. Impact of global geographic region on time in therapeutic range on warfarin anticoagulant therapy: data from the ROCKET AF clinical trial. J Am Heart Assoc. 2013; 2: e000067.

10. White HD, Gruber M, Feyzi J, Kaatz S, Tse HF, Husted $\mathrm{S}$, Albers GW. Comparison of outcomes among patients randomized to warfarin therapy according to anticoagulant control: results from SPORTIF III and V. Arch Intern Med. 2007; 167: 239-45.

11. Cotte FE, Benhaddi H, Duprat-Lomon I, Doble A, Marchant $\mathrm{N}$, Letierce A, Huguet M. Vitamin K antagonist treatment in patients with atrial fibrillation and time in therapeutic range in four European countries. Clin Ther. 2014; 36: 1160-8.

12. Caldeira D, Cruz I, Morgado G, Stuart B, Gomes C, Martins $\mathrm{C}$, Joao I, Pereira H. Evaluation of time in therapeutic range in anticoagulated patients: a single-center, retrospective, observational study. BMC Res Notes. 2014; 7: 891.

13. Santos PC, Soares RA, Strunz CM, Grinberg M, Ferreira JF, Cesar LA, Scanavacca M, Krieger JE, Pereira AC. Simultaneous use of amiodarone influences warfarin maintenance dose but is not associated with adverse events. J Manag Care Pharm. 2014; 20: 376-81.

14. Schwarz UI, Ritchie MD, Bradford Y, Li C, Dudek SM, Frye Anderson A, Kim RB, Roden DM, Stein CM. Genetic determinants of response to warfarin during initial anticoagulation. N Engl J Med. 2008; 358: 999-1008.

15. Santos PC, Dinardo CL, Schettert IT, Soares RA, Kawabata Yoshihara L, Bensenor IM, Krieger JE, Lotufo PA, Pereira AC. CYP2C9 and VKORC1 polymorphisms influence warfarin dose variability in patients on long-term anticoagulation. Eur J Clin Pharmacol. 2013; 69:789-97. 
16. Okumura K, Komatsu T, Yamashita T, Okuyama Y, Harada M, Konta Y, Hatayama T, Horiuchi D, Tsushima E. Time in the therapeutic range during warfarin therapy in Japanese patients with non-valvular atrial fibrillation. - A multicenter study of its status and infuential factors. Circ J. 2011; 75: 2087-94.

17. Skeppholm M, Friberg L. Adherence to warfarin treatment among patients with atrial fibrillation. Clin Res Cardiol. 2014; 103: 998-1005.

18. WHO (World Health Organization. Definition of an older or elderly person. http://www.who.int/healthinfo/survey/ ageingdefnolder/en/. Accessed 25 Nov 2015.

19. Pamboukian SV, Nisar I, Patel S, Gu L, McLeod M, Costanzo MR, Heroux A. Factors associated with nonadherence to therapy with warfarin in a population of chronic heart failure patients. Clin Cardiol. 2008; 31: 30-4.

20. Witt DM, Delate T, Clark NP, Garcia DA, Hylek EM, Ageno W, Dentali F, Crowther MA. Nonadherence with INR monitoring and anticoagulant complications. Thromb Res. 2013; 132: e124-30.

21. Waterman AD, Milligan PE, Bayer L, Banet GA, Gatchel SK, Gage BF. Effect of warfarin nonadherence on control of the International Normalized Ratio. Am J Health Syst Pharm. 2004; 61: 1258-64.

22. Huang LH. Medication-taking behavior of the elderly. Kaohsiung J Med Sci. 1996; 12: 423-33.

23. Monane M, Bohn RL, Gurwitz JH, Glynn RJ, Levin R, Avorn J. Compliance with antihypertensive therapy among elderly Medicaid enrollees: the roles of age, gender, and race. Am J Public Health. 1996; 86: 1805-8.

24. Cohen MJ, Shaykevich S, Cawthon C, Kripalani S, Paasche-Orlow MK, Schnipper JL. Predictors of medication adherence postdischarge: the impact of patient age, insurance status, and prior adherence. J Hosp Med. 2012; 7: 470-5

25. Pastori D, Pignatelli P, Saliola M, Carnevale R, Vicario T, Del Ben M, Cangemi R, Barillà F, Lip GY, Violi F. Inadequate anticoagulation by Vitamin $\mathrm{K}$ Antagonists is associated with Major Adverse Cardiovascular Events in patients with atrial fibrillation. Int J Cardiol. 2015; 201: 513-6.

26. Rose AJ, Ozonoff A, Henault LE, Hylek EM. Warfarin for atrial fibrillation in community-based practise. J Thromb Haemost. 2008; 6: 1647-54.

27. Bhandari VK, Wang F, Bindman AB, Schillinger D. Quality of anticoagulation control: do race and language matter? J Health Care Poor Underserved. 2008; 19: 41-55.

28. Shen AY, Yao JF, Brar SS, Jorgensen MB, Wang X, Chen W. Racial/Ethnic differences in ischemic stroke rates and the efficacy of warfarin among patients with atrial fibrillation. Stroke. 2008; 39: 2736-43.
29. Li C, Schwarz UI, Ritchie MD, Roden DM, Stein CM, Kurnik D. Relative contribution of CYP2C9 and VKORC1 genotypes and early INR response to the prediction of warfarin sensitivity during initiation of therapy. Blood. 2009; 113: 3925-30.

30. Gage BF, Waterman AD, Shannon W, Boechler M, Rich MW, Radford MJ. Validation of clinical classification schemes for predicting stroke: results from the National Registry of Atrial Fibrillation. JAMA. 2001; 285: 2864-70.

31. Lip GY, Nieuwlaat R, Pisters R, Lane DA, Crijns HJ. Refining clinical risk stratification for predicting stroke and thromboembolism in atrial fibrillation using a novel risk factor-based approach: the euro heart survey on atrial fibrillation. Chest. 2010; 137: 263-72.

32. Santos PC, Marcatto LR, Duarte NE, Soares RA, Strunz CM, Scanavacca M, Krieger JE, Pereira AC. Development of a pharmacogenetic-based warfarin dosing algorithm and its performance in Brazilian patients: highlighting the importance of population-specific calibration. Pharmacogenomics. 2015; 16: 1-12.

33. Ansell J, Hirsh J, Hylek E, Jacobson A. Pharmacology and management of the vitamin $\mathrm{K}$ antagonists: American College of Chest Physicians Evidence-Based Clinical Practice Guidelines (8th Edition). Chest. 2008; 133: 160S-198S.

34. Rosendaal FR, Cannegieter SC, van der Meer FJ, Briet E. A method to determine the optimal intensity of oral anticoagulant therapy. Thromb Haemost. 1993; 69: 236-9.

35. Jetter A, Kinzig-Schippers M, Skott A, Lazar A, TomalikScharte D, Kirchheiner J, Walchner-Bonjean M, Hering U, Jakob V, Rodamer M, Jabrane W, Kasel D, Brockmoller J, et al. Cytochrome P450 2C9 phenotyping using low-dose tolbutamide. Eur J Clin Pharmacol. 2004; 60: 165-71.

36. Sconce EA, Khan TI, Wynne HA, Avery P, Monkhouse L, King BP, Wood P, Kesteven P, Daly AK, Kamali F. The impact of CYP2C9 and VKORC1 genetic polymorphism and patient characteristics upon warfarin dose requirements: proposal for a new dosing regimen. Blood. 2005; 106: 2329-33.

37. Scott SA, Khasawneh R, Peter I, Kornreich R, Desnick RJ. Combined CYP2C9, VKORC1 and CYP4F2 frequencies among racial and ethnic groups. Pharmacogenomics. 2010; 11: 781-91.

38. Ahmad S. Lovastatin: Warfarin interaction. Arch Intern Med. 1990; 150: 2407. 